\title{
ANÁLISE DE UMA EXPERIÊNCIĀ DE TREINAMENTO DE PESSOAL AUXILIAR DE ENFERMAGEM
}

\author{
Maria Aparecida Minzoni * \\ Zilma Ramos de Oliveira ** \\ Antonia Regina F. Rodrigues **
}

\section{1 - Introdução}

Com as rápidas mudanças introduzidas na sociedade devido áo progresso técnico-científico, uma educação contínua dos profissionais em todas as áreas, tornou-se necessária.

Assim, de modo geral, as instituições de saúde procuram treinar continuamente seu pessoal que está em atividade, de forma que ele esteja sempre pronto a utilizar as novas técnicas e conhecimentos que são introduzidos nesse campo.

$\mathrm{Na}$ área da educação isso se fez tão necessário quanto $\mathrm{na}_{\mathrm{a}}$ área da saúde, mas houve uma preocupação em definir a terminologia comumente usada quando se trabalha nesse campo.

A educação será contínua quando ocorre de forma permanente seja, ou não, planejada. Conforme os objetivos propostos, ela envolve os conceitos de treinamento, reciclagem e atualização.(1)

Fala-se em treinamento quando o indivíduo está sendo preparado para a aquisição de uma habilidade específica. Ex: aprender a manipular uma nova máquina, a executar uma nova técnica. $R e-$ ciclagem é utilizado quando a preparação do indivíduo é num sentido mais amplo, para o exercício de uma nova função. Esse termo refe-

- Enfermeira Assistente Doutor do Departamento de Enfermagem Psiquiátrica e Ciências Humanas da Escola de Enfermagem de Ribeirão Preto, USP.

** Pedagoga e Enfermeira assistente-voluntária do Departamento de Enfermagem Psiquiátrica da Escola de Enfermagem de Ribeirão Preto, USP, respectivamnte.

- Os termos atendentes e pessoal auxiliar de enfermagem serão utilizados como sinônimos. 
re-se especialmente ao preparo das pessoas para uma mudança completa de atividade. Exige a aprendizagem de um conjunto de habilidades novas a serem aplicadas num contexto totalmente novo. Ex: um grupo de enfermeiras que são preparadas para executarem funções de supervisora de unidade. O processo de atualização, por sua vez, visa renovar ou criar comportamentos novos de acordo com o nível de evolução da sociedade. Isto é, colocar o indivíduo a par dos achados mais recentes quer num contacto técnico-científico, quer em relação ao contexto cultural geral.

De modo geral, treinamento e reciclagem são empregados como sinônimos e se referem ao processo de aquisição de novas habilidades e conhecimentos.

Para efeitos do presente trabalho utilizaremos o termo treinamento indiscriminadamente, embora estejamos conscientes de que na experiência a ser analisada nosso planejamento envolvia tanto o processo de treinamento, quanto de reciclagem e em alguns aspectos de atualização.

\section{2 - Relato da experiência}

Há muito tempo temos nos preocupado com o problema de orientação e melhoria do pessoal auxiliar de enfermagem* que trabalha em hospital psiquiátrico. Essa preocupação se prende ao fato de termos observado, através de nossa experiência, em diversas instituições desse gênero, que este pessoal não tem preparo em enfermagem, quer sob o aspecto geral básico quer em relação ao tratamento específico ao doente mental. Além disso, pensávamos que uma modificação na forma de cuidar do paciente, dependia também. em larga escala, do pessoal de enfermagem que está continuamente com ele, e não somente, da organização social da instituição.

Durante muitos anos executamos programas de treinamento nesses hospitais. Aparentemente os resultados eram positivos, mas ao retornarmos à instituição verificaremos que não houvera modificações. Então, outra hipótese nos ocorreu. Para haver mudanças seria necessário que o pessoal de enfermagem sentisse os mecanismos que estão envolvidos no comportamento humano e, em conseqüência, no comportamento do doente.

Ainda havia outro ponto que representava o foco de nossa atenção. O tipo de assistência que estava e continua sendo dada ao paciente internado em hospitais psiquiátricos, não é considerado o melhor.(2) Ela precisa ser modificada.

Baseados nesses quatro pontos: desconhecimento técnico-científico do atendente; o atendente como elemento essencial de mudança; a necessidade de mobilizar os valores dos atendentes em relação a 
doença mental; e a crença na inadequação do tipo de assistência psiquiátrica que vem se realizando, planejamos e organizamos um curso de treinamento para atendentes de hospitais psiquiátricos.

O curso foi programado com aulas teóricas que desenvolviam diversos assuntos considerados importantes como conhecimentos básicos para quem se propõe a modificar sua atuação. No seu desenvolvimento, a ênfase sempre foi colocada na importância do relacionamento interpessoal atendente-paciente e na maior flexibilidade das regras e normas hospitalares, permitindo ao paciente ter mais liberdade de ação, atitudes mais independentes e possibilidades de manter sua auto-imagem.

Foi programado, ao lado das apresentações teóricas, um pequeno grupo experimental para discussões semanais de dúvidas, emoções e sentimentos dos participantes. Esse grupo foi selecionado segundo as variáveis idade, sexo, tempo de serviço e escolaridade.

Pretendiamos, através das discussões, que os elementos do grupo, primeiramente, tomassem conhecimento de si mesmos como pessoa com qualidades e dificuldades, das quais muitos não lhes eram claramente perceptíveis. Depois dessa fase, pensávamos levá-los a perceber que o paciente também é uma pessoa igual a eles, apresentando diferença na forma e intensidade de expressar pensamentos e emoções. Ainda procuramos mostrar-lhes como cada pessoa pode "perder seu controle" em várias situações da vida diária, assim como o faz o paciente.

Após quase três meses de reuniões semanais com o grupo, ele se dissolve ao mesmo tempo em que terminam as aulas teóricas. Isto foi planejado, porquanto o objetivo das aulas teóricas era oferecer conhecimentos (área cognitiva) e o do grupo era lidar com os aspectos afetivos e os valores, a partir da idéia de que o conhecimento já tinha sido adquirido. Quando o grupo interrompeu seus encontros semanais havíamos chegado a atingir, apenas, a fase de auto-conhecimento.

Nesse peroído trabalhamos com esse pessoal, com essas idéias, acreditando que os resultados seriam uma modificação em suas atitudes para com o paciente e conseqüente interferência na organização social da instituição. E então, deixamo-los atuando, sozinhos no seu local de trabalho.

Depois de alguns meses voltamos a observar esses atendentes, em atividade, na situação hospitalar e verificamos que não houve modificações de comportamento como era esperado. Mais uma vez estavamos frente a um fracasso e interessava-nos, agora encontrar os motivos que levaram a isso, desde que havíamos sido cuidadosas no planejamento. 


\section{3 - Análise da experiência}

Para que essa análise se tornassee mais clara e compreensiva pensamos em apresentar, primeiramente, uma exposição teórica esquematizada do processo de mudança e das características dos dois tipos de assistência psiquiátrica que se contrapõem.

3.1. Educação continua como processo de mudança - Se se pensa que tanto o treinamento, quanto a reciclagem ou a atualização envolvem a introdução de inovações pode-se, então, considerar a educação contínua como um processo de mudança.

Quando se treina o indivíduo para o uso de uma nova máquina ou a execução de novos papéis, estamos lidando com os aspectos da nova aprendizagem e, também, com os valores, normas, padrões e hábitos de cada pessoa que participa do processo. Portanto, qualquer que seja o objetivo a ser atingido num programa de treinamento, este deve ser feito com conhecimento do comportamento humano e dos processos de mudança.

Num processo de mudança podem ser usadas algumas estratégias e conforme os objetivos propostos podem estar centralizadas no grupo, nas pessoas e suas relações, na instituição ou inteiramente no indivíduo.

Benne e Birbaun(1) procuraram identificar alguns principios de mudança que são apresentados, resumidamente, a seguir:

- para mudar um sistema ou parte desse sistema, aspectos relevantes do ambiente também devem ser mudados;

- para mudar o comportamento em qualquer nível de uma organização hierárquica é necessário atingir mudanças complementares acima e abaixo do nível;

- o ponto a ser escolhido para inciar uma mudança é aquele em que existe alguma ansiedade. A ansiedade indica uma insatisfação em relação ao "status quo";

- nem sempre convém começar a mudança pelo ponto mais sensível. Feito o diagnóstico da situação é necessário avaliar o grau de ansiedade nos pontos onde a mudança é desejada;

- devem ser levados em conta, na introdução de mudanças, tanto a organização formal como a informal;

- a efetividade de uma inovação está geralmente relacionada com o grau em que os membros dos diversos níveis hierárquicos, estão envolvidos no processo. 
Outro aspecto importante no planejamento de um programa uesse tipo seria verificar as possibilidades de que ele seja efetivo. Para isso pode-se levantar algumas questões tais como:

- os objetivos de aprendizagem são apropriados?

- os indivíduos estão prontos para se envolver no processo?

- as pessoas-chave estão envolvidas?

- os membros-participantes estão adequadamente preparados e orientados quanto ao treinamento?

\section{- a participação é voluntária?}

Ainda um outro ponto a ser lembrado se refere às resistências para a mudança. Estas podem estar relacionadas aos indivíduos como pessoa, às expectativas dos participantes quanto ao que o treinamento oferece, aos mecanismos de defesa devido ao medo de perda de jdentidade, à colaboração entre participantes e o agente de muủança (treinador).

Assim, quando se pensa na realização de qualquer desses programas (treinamento, reciclagem ou atualização) é importante estar atento as técnicas de aprendizagem a serem utilizadas, quanto aos valores, normas e padrões dos indivíduos, dos grupos ou das organizações envolvidas.

3.2. Evolução da assistência psiquiátrica - O conceito de docnça mental e consequentemente a sua assistência tem evoluido através do tempo, de acordo com a situação sócio-cultural onde se insere.

No momento, o que se observa é uma atenção mais humanitária ao paciente em relação ao passado, embora se considere, ainda que o doente deve ser mantido em hospitais, isolado da sociedade. $O$ doente mental é visto como um ser humano, com problemas bio-psicológicos, necessitando de tratamento, além dos cuidados devidos a qualquer doente por ser uma pessoa, como: vestuário, alimentação, abrigo e vigilância.(3)

Nessa situação, o ambiente hospitalar está organizado em sua estrutura administrativa e social de forma que o paciente é levado a comportamentos de dependência, submissão, conformidade e perda de identidade, por falta de estímulos que o levem a conservar sua própria imagem.(4)

Desse modo, os elementos de enfermagem, constituídos em sua maioria por pessoal auxiliar, se restringem à execução de funções técnicas, quanto à aplicação de tratamento; de atendimento de necessidades básicas no que se refere a abrigo, alimentação e higiene; de vigilância para proteção à vida do paciente; e algumas vezes, a proporcionar possibilidades de recreação e ocupação aos internados Esse tipo de assistência tem sido comumente chamado de custodial. 
Nos últimos 20 anos surgiu um movimento para reestruturação e mudanças nos hospitais psiquiátricos, em contraposição à assistência vigente. Esse movimento propõe uma visão mais humanitária em relação a paciente, mostrando que ele tem ações e reações semelhantes às das demais pessoas e que conserva muitos aspectos sadios em sua personalidade, os quais necessitam estimulação contínua.

A partir desses conceitos, deu-se mais importancia às necessidades psicológicas e sociais dos pacientes e a organização social da instituição é considerada como um instrumento terapêutico tanto quanto as terapias somáticas e psíquicas. O ambiente hospitalar é organizado de forma que o doente possa utilizar os aspectos sadios da sua personalidade. Deixa de ser restrito e passa a estimular o doente a tomar decisões, ter iniciativa, ser independente e a aprender a respeitar as regras sociais da instituição, qualificados por todos como um bem comum.

O relacionamento é um elemento dos mais importantes como fator terapêutico, e o pessoal de enfermagem deve executar funções mais elaboradas e mais complexas que as exigidas no tipo de assistência custodial. Assim, além dos cuidados higiênicos e técnicos, o pessoal de enfermagem deve ter capacidade de compreender 0 comportamento do paciente e tomar atitudes adequadas em relação a ele. Por outro lado ele deve favorecer a flexibilidade das condições estabelecidas pela organização social da instituição, tornando o ambiente terapêutico, não um lugar de isolamento. A essa assistência tem-se denominado de terapêutica.

3.3. Análise dos motivos - Estudando, agora, a experiência realizada e confrontando-a com os modelos teóricos no que se refere ao processo de mudança e aos tipos de assistência focalizados, é possível compreender os motivos que levaram a resultados negativos.

Sob o ponto de vista do treinamento realizado verificamos que ele se baseou nos quatro pontos indicados no item 2 - relato da experiência - e que estes abrangem tanto aspectos didáticos quanto psico-sociais.

Quanto aos aspectos didáticos da aprendizagem averiguamos que não houve muitos erros. Foi programada uma parte da mesma onde eram dadas informações para que os participantes pudessem tomar conhecimento da teoria e prática da enfermagem, desde que eram pessoas sem preparo nesse campo. Ao mesmo tempo preocupou-nos a abordagem em relação às mudanças de atitudes que envolviam os valores e opinióes de cada participante. Para isso foi utilizado o grupo de discussão que é uma técnica que permite chegar-se a uma 
compreensão melhor de aspectos mais profundos que podem interferir em nosso comportamento diário.

Por outro lado, constatamos que não houve um bom reajustamento do plano quando o tempo não foi suficiente para atingir todos os objetivos propostos. Para que a aprendizagem fosse satisfatória o grupo deveria ter completado as três fases previstas: auto-conhecimento, compreensão do outro e compreensão do comportamento do doente mental. E, na realidade, o grupo, no tempo previsto, apenas o auto-conhecimento. Ainda em relação ao tempo, verificamos que havia muito interesse e colaboração dos elementos do grupo para que ele se prolongasse; no entanto, optamos por encerrar a aprendizagem, não fugindo ao planejamento inicial.

Outro aspecto a ser comentado, diz respeito a um dos enfoques feitos durante as reuniões de grupo; este se refere ao fato de tentarmos mostrar que todas as pessoas têm partes doentes em suas personalidade; com isso a idéia que ficou foi de que "todas as pessoas são doentes", quando o que desejavamos era que se fixasse o conhecimento de que "todos os doentes tem partes sadias". Com isso foi aumentada a ansiedade e o medo, dos elementos do grupo, de se parecerem com os doentes mentais.

Quanto aos aspectos psico-sociais nossos erros foram maiores c sua análise é mais complexa.

A rigidez da estrutura administrativa e organização social das instituições custodiais se constitue no ponto central e, poderíamos mesmo dizer, na origem dos demais elementos envolvidos no processo e que serão analisados a seguir.

Nessa estrutura, o pessoal auxiliar de enfermagem ocupa uma posição quase insignificante, no sentido de poder atuar como agente de mudança.

Considerando-se a hierarquia estabelecida, esse pessoal está colocado na base da pirâmide, portanto sem poder de decisão e de mando e ainda sofrendo as pressões que partem de todos os demais elementos que se encontram nas posições acima dele. Como não se espera dele a execução de tarefas complexas, capacidade de iniciativa e atitudes independentes, muito pouco é exigido. Por isso é um pessoal não selecionado, não técnico e sem treinamento.(2)

Se nos lembrarmos que a finalidade do treinamento era provocar uma mudança da assistência custodial em direção á terapêutica, poderemos entender melhor o que ocorreu. O treinamento foi centralizado inteiramente no indivíduo, quando se enxergava como ponto inicial de mudança, o pessoal auxiliar de enfermagem. No entanto, este pessoal estando em atividade numa instituição onde a organização social é do tipo acima descrito, ela mesmo impedia qual- 
quer movimento seu, nesse sentido. Pelo contrário, reforçava atitudes custodiais mostrando a ineficiência e nulidade de seus esforços para tomar atitudes mais liberais em relação ao paciente.

Como o treinamento foi centralizado no indivíduo, não houve interferência nossa no ambiente total, portanto na organização formal e informal da instituição. Enquanto isso esses fatores estavam interferindo continuamente no pessoal em treinamento. Assim, também não nos preocupamos, por não ser possível, em atuar nos outros níveis da escala hierarquica. Como não havia interesse das pessoas-chave, nesse processo de mudança, estas não participaram do treinamento.

Por tudo isso a aprendizagem teve um efeito iatrogênico sobre as atendentes que dela participaram. Esse efeito foi verificado quando da observação posterior deste pessoal.

O atendente, na realidade hospitalar, é o ponto mais sensível, porquanto além de sofrer as pressões de cima para baixo é o elemento que mantém contato quase permanente com os internados. Ao mesmo tempo não tem preparo técnico-científico e algumas vezes faltam-lhe qualidades humanas(5) para manejar as situações; nas reuniões grupais ele pôde sentir a possibilidade e a necessidade de mudar suas atitudes em relação aos doentes; Isto, provavelmente, provocou sentimentos de culpa pelas atitudes que vinha tomando, c ansiedade no sentido de modificar seu comportamento.

Em resumo, de um lado encontamos um grupo vulnerável, ansioso e sem apoio e do outro a instituição forte com suas normas e regulamentos, auto-suficiente e detentora do poder.

Frente a esse quadro, é possível que o atendente tivesse apenas duas escolhas: negar ou aceitar a veracidade do que estava aprendendo. Se sua atitude é de negação, ele se adapta a rotina diária sem qualquer tentativa de fazer mudanças. Se sua atitude é de aceitação ele percebe a necessidade de mudanças mas sem encontrar possibilidades de executá-las, então sua ansiedade aumenta. Para aliviar essa ansiedade ele deverá usar outros mecanismos: pode se adaptar novamente aos padrões vigente e volta ao nível anterior de comportamento - atitude conformista; pode revoltar-se contra a instituição - atitude revolucionária. Nesta atitude ele não terá condições de continuar com os comportamentos anteriores, então deverá reelaborar todo seu esquema de vida e, provavelmente, deixar o emprego. Ou então pode recorrer a outros mecanismos de defesa como a "formação reativa", não podendo modificar, passa a não atuar. Seu comportamento volta então a níveis mais baixos que os anteriores ao treinamento. $\mathbf{E}$ algumas dessas situações ocorreram na realidade. 


\section{4 - Conclusões}

Parece-nos que muito pouco tempo a crescentar ao que foi exposto. Lembramos, apenas, que no campo da assistência psiquiátrica, a necessidade de mudança tem sido sentida pelos profissionais que procuram acompanhar a evolução da psiquiatria. Por outro lado, verificamos que já não é possível pensar-se em treinamento sem previsão das possíveis conseqüências.

Consideramos que nosso trabalho foi útil pela experiência que nos trouxe, principalmente pela oportunidade de uma avaliação crítica de nossa atuação e dos resultados. Mas, de tudo isso ainda restam duas questões que não foram respondidas: " $E$ válido tentar uma mudança quando as forças que determinam a política de assistência não estão voltados para isso?". "Não será preferível treinar o pessoal auxiliar de enfermagem para ser um bom técnico na assistência custodial, a deixá-lo em conflito ou sem qualquer tipo de treinamento?". Por outro lado, lembramos que é uma responsabilidade da Universidade acompanhar o progresso técnico-científico e divulgá-lo.

\section{5 - Bibliografia}

1 - GATTI, B.A., MELLO, G.N. de e BERNARDES, N.M.G. - Treinamento, reciclagem, educação permanente. Cadernos de pesquisa. Fundação Carlos Chagas, 4: 3 a 8, outubro, 1972.

2 - MINZONI, M.A., et allii - Assistência de enfermagem psiquiátrica no estado de São Paulo. Apresentado no XI Congresso Nacional de Psiquiatria, Neurologia e Higiene Mental, São Paulo, 1973.

3 - BLAYA, M. - Tratamento hospitalar com orientação psicanalítica, Porto Alegre, Globo, 1960. (Tese de livre-docência).

4 - MINZONI, M.A. - Assistência de enfermagem psiquiátrica. Ribeirăo Preto, 1971. (Tese de doutoramento). 